\title{
Teoria e Prática de uma agenda de investigação sociológica em ciência e tecnologia
}

PREMEBIDA, A.; NEVES, F.M.; DUARTE, T.R. (orgs.). Investigaçóes contemporâneas em estudos sociais da ciência e da tecnologia. Jundiaí: Paco Editorial, 2015, v.1., 325p.

EDEMILSON PARANÁ"

Em oposição a toda a sorte de formulações empiristas, realistas e neopositivistas, os trabalhos reunidos no livro, de modo geral, gravitam em torno da defesa de uma tese central que - não sem produzir grande impacto no momento de seu aparecimento - vem se tornando, a essa altura, quase hegemônica na sociologia do conhecimento, da ciência e da tecnologia; qual seja, a de que a produção do saber, das teorias e das técnicas não pode ser devidamente compreendida e explicada senão em relação com interesses, embates, controvérsias; em suma, em face dos contextos e conteúdos sociais aos quais estão inseparavelmente relacionadas e das quais advém. Assim dito, sem os devidos qualificativos, é certo, a assertiva correria o risco de manter-se vaga ou meramente retórica, sobretudo a essa altura de desenvolvimento e sofisticação dos trabalhos produzidos no campo da sociologia da ciência e do conhecimento. Este, no entanto, não é caso do conjunto de textos organizados por Adriano Premebida, Fabrício Monteiro Neves e Tiago Ribeiro Duarte na coletânea Investigações Contemporâneas em Estudos Sociais da Ciência e Tecnologia (Paco Editorial, 2015). Seguindo à risca a diretiva de que o argumento

\footnotetext{
* Universidade de Brasília, Brasil.
} 
a respeito da contextualidade histórico-social da produção do conhecimento deve estar amparado em investigações de natureza empírica, a construção social de que se fala é aqui problematizada e qualificada em discussões teórico-filosóficas, mas, também, operacionalizada e ilustrada por meio de pesquisas inovadoras - algo que demonstra a vitalidade dos Estudos Sociais da Ciência e Tecnologia (ESCT), dentro e fora do Brasil.

O que não quer dizer, apesar do fio condutor que, graças à curadoria dos organizadores, traz organicidade à coletânea, que os trabalhos todos concordem entre si, ou façam apenas repetir monocordicamente a referida tese. Pelo contrário. Uma das riquezas da obra reside justamente no debate interno a que, de texto em texto, ora implícita, ora explicitamente, o leitor é levado a conhecer - algo que, ademais, reforça seu caráter pedagógico, sobretudo para aqueles que pela primeira vez tomam contato com tal perspectiva de tratamento sociológico da ciência. Seguindo essa linha de trabalho, os autores fazem reforçar tendência, que remete às últimas décadas do século XX, de levar para além das políticas e instituições científicas e tecnológicas os objetos de estudos sociológicos da ciência, de modo a endereçar reflexões a respeito do próprio produto ou conteúdo do conhecimento. Temas fundamentais, e que estão na ordem do dia, como a chamada virada historicista e sua eventual influência nos estudos sociais da ciência, os fundamentos filosóficos e conceituais do Programa Forte em sociologia da ciência, o papel da realidade empírica na determinação das teorias científicas, a inseparabilidade entre natureza e sociedade e o agenciamento material na construção de novas abordagens explicativas são, um a um, enfrentados com maestria.

Se é verdade que as discussões desenvolvidas nesta chave ganham cada vez mais espaço e interesse no Brasil, é igualmente certo que o campo ainda carece, por aqui, do desenvolvimento de estudos e traba- 
Ihos provenientes de investigações empíricas, bem como, e inseparavelmente, de maior institucionalização acadêmica. Por essa razão, a obra é duplamente justificada: ao apresentar com clareza uma "nova" agenda de pesquisas e, junto dela, sua vitalidade e viabilidade atestada em bem-sucedidos estudos de caso.

Para tanto, o livro está dividido basicamente em duas partes. A primeira delas, além de um panorama histórico dos ESCT, cobre, como mencionado, alguns de seus mais importantes debates teóricos. A necessária complementação vem na segunda parte, que, ao trazer uma gama de estudos de caso sobre distintos temas, contribui para produzir, ao fim, um todo bem-acabado.

Logo na introdução, o resgate da jornada de surgimento e desenvolvimento dos estudos sociais da ciência é feito por Harry Collins, um dos principais representantes da chamada Escola de Bath ou Programa Empírico do Relativismo (EPOR - Empirical Programme of Relativism) conhecido por ter se dedicado, em especial, ao estudo de controvérsias científico-tecnológicas. Para além do capítulo introdutório de sua autoria, o livro traz ainda, no posfácio, uma entrevista com o sociólogo, conduzida por Rafael Antunes Almeida.

Correndo o risco de incorrer em certo generalismo, é possível observar, ao longo do livro, algum alinhamento ou proximidade com as posições aqui defendidas por Collins. Trata-se de um mérito, visto que esta é uma abordagem robusta no interior dos Science Studies, conforme demonstram Tiago Duarte e Carlos Maia em contraposição às formulações e críticas provenientes de autores como Michel Callon e Bruno Latour. Assim, em face da importância de tais argumentos para o conjunto geral da obra, cumpre nos determos ante algumas de suas principais assertivas.

Retomando argumento mobilizado em texto anterior (Collins; Evans, 2002), Collins divide o percurso de desenvolvimento dos estudos da ciência em duas fases, ou "ondas", advogando pela necessidade de uma terceira. 
A "primeira onda" foi o período marcado, no pós-guerra, pela proeminência de Merton e os filósofos da ciência, culminando em Popper e Kuhn ${ }^{1}$. Uma vez que, nessa acepção, a ciência era o modo predominante e legítimo de conhecimento, tratou-se de compreender que tipo de sociedade, governada por quais instituições, seria mais adequada para sua prática. A conclusão asseverava que as normas da ciência eram as normas da democracia e, por isso, sociedades de tipo liberal-democrática seriam mais propícias à prática científica.

A "segunda onda", de acordo com Collins, começa na década de 1970, e busca desconstruir a suposta prioridade epistemológica da ciência. Ao demonstrar o caráter sociocontextual do conhecimento em estudos de casos, por meio de novas técnicas e abordagens, corroborou a ideia de que "não havia nada de especial na ciência" (p.19). Tal "onda", conforme argumenta o autor, não passaria incólume pelas disputas entre os movimentos que se formaram em seu interior, sendo a mais notável, como se sabe, o racha entre David Bloor e Bruno Latour. Nessa via, Collins sumariza os últimos quarenta anos dos Science Studies, mencionando além do Programa Empírico do Relativismo (EPOR) e a sociologia da tecnologia (SCOT), a Teoria do Ator-rede (ANT) e as abordagens feministas - não sem deixar de apontar, com aparente pesar, que "o movimento como um todo foi, em certa medida, varrido pela ampla corrente do pós-modernismo" (p.18).

Produto desse percurso, emerge, no argumento de Collins, pela necessidade de uma "terceira onda", posição menos iconoclasta, e, de certo, mais madura, no tratamento do conhecimento científico, para quem "uma completa desconstrução da ideia de ciência e tecnologia, fazendo com que todos sejam vistos como detentores de direitos iguais quando se trata de conhecimento técnico (aquilo que chamamos de "populismo tec-

1 Este é apontado como responsável por uma transição no campo ao trazer a dimensão histórica para dentro das reflexões sobre a ciência. 
nológico") é um prospecto aterrorizante" (p.20)². Collins põe-se, assim, o problema de entender o valor da ciência - ainda que esta não possua nenhuma justificação epistemológica especial. Em busca de resolvê-lo, sua "terceira onda" combina os estudos de expertise e a experiência do "modernismo eletivo".

Tais estudos buscam mapear o que é expertise e quem são os experts no que tange aos problemas científicos e tecnológicos ("quem sabe o que está falando"), de modo que as melhores decisões tenham como ponto de partida uma discussão entre tais experts em interação com a participação cidadã, que permanece, em última instancia, com a escolha política em suas mãos.

Vinculada a essa proposição - de que as escolhas democráticas em ciência e tecnologia (C\&T) devem ser feitas levando em conta aquilo que os melhores experts têm a dizer - aparece o "modernismo eletivo", ou seja, a ideia de que "as sociedades devem ser organizadas para permitir que os experts debatam e tirem suas conclusões claramente, de modo que elas possam ser inseridas no debate político sem supressão ou distorção" (p.21). Assim, conforme defende Collins, as velhas normas da ciência (aquelas descritas pela "primeira onda") voltam a adquirir, ainda que por outra via, papel de destaque, e, com isso, a ciência adentra com clareza ao campo das políticas públicas. "O critério de demarcação de Popper e o critério de demarcação associado ao positivismo são ressuscitados como propriedades de um debate entre experts" (idem), ainda que, aqui, estes não devam ser

\footnotetext{
2 Para contextualizar os problemas que o fazem questionar as lacunas da "segunda onda" e, assim, dirigir-se na direção dos estudos de expertise (característicos da "terceira onda"), Collins relata, em entrevista publicada no posfácio deste mesmo livro (pp. 320-1), episódio notável: “Novamente, um dia, estava voltando de uma conferência (...) E um dos antropólogos disse-me: 'Já que você é relativista, como o relativismo ajuda-nos a decidir sobre o que dizer aos homens sul-africanos que acreditam que o caminho para curar a AIDS é ter uma relação sexual com uma virgem? O que o relativismo tem para dizer-nos sobre este problema? ' Eu percebi que não tinha uma resposta. Eu não sabia o que o relativismo teria para dizer ao debater-se com um problema como este. (...) Foi este tipo de quebra-cabeça que me levou a pensar e a preocupar-me sobre como responder a estas questões como um sociólogo".
} 
tratados como critérios puramente lógicos, mas como "características da forma de vida" (p.21) que devemos valorizar. As referências, nesse particular, são explícitas: trata-se de sociedades em que o debate livre e o conhecimento público são regidos de acordo com as normas apontadas por Robert Merton, em consonância com o horizonte normativo presente nas ideias de Jurgen Habermas (situações ideais de comunicação livre).

Seguindo a reflexão sobre os estudos sociais da ciência, Luiz Henrique de Lacerda Abrahão, no capítulo intitulado "Kuhn e Feyerabend: antagonismos, aproximações e os estudos sociais da Ciência", volta aos fundamentos daqueles que têm sido considerados os principais precursores dos ESCT. Depois de um estudo cuidadoso e esclarecedor dos pontos de semelhança e antagonismo entre as principais teses de tais autores, Abrahão apresenta e discute a rejeição de ambos ao "Programa Forte" de David Bloor para, por fim, discutir a real medida - que considera "essencialmente ambígua", parte que é de uma "incerteza genealógica" - das heranças de Kuhn e Feyerabend para os estudos sociais da ciência (SSK). A partir dessa conclusão, advoga pela necessidade de reconhecer os fundamentos, tratar as eventuais inconsistências, alargar os domínios de aplicação e realizar a difusão dos SSK, em detrimento de esforços presos a estritos "interesses arqueológicos" da sociologia da ciência como disciplina.

No capítulo seguinte, "A sociologia do conhecimento de E. Durkheim e do Programa Forte", Tiago Ribeiro Duarte discute os pontos de aproximação e distanciamento entre a sociologia de Durkheim (das religiões e do conhecimento) e o Programa Forte em sociologia da ciência. O resgate ampara-se em David Bloor, um dos fundadores deste Programa, para quem Durkheim teria sido uma de suas principais influências. Seguindo Bloor, Duarte defende que a abordagem de Durkheim sobre as religiões deve ser estendida à ciência, de modo a explicar sociologicamente o conteúdo das teorias científicas (algo que o próprio Durkheim teria ne- 
gligenciado ao caracterizar a ciência como dotada de autonomia perante a sociedade e, desse modo, produtora de conhecimento objetivo e impessoal sobre a realidade empírica). Depois de uma análise a respeito de como a sociologia forte compreende a relação entre as teorias científicas, natureza e sociedade, o autor procura demonstrar a importância que a realidade empírica desempenha na determinação das teorias científicas nesta vertente, de modo a responder às críticas formuladas a este respeito, a partir de caminhos distintos, por Thomas Kuhn e Bruno Latour.

Seguindo argumento análogo, aprofundando-o, Carlos Maia Alvarez produz uma vigorosa crítica ao princípio da simetria generalizada e à teoria do ator-rede (ANT) no capítulo "Os impasses conceituais de Latour: o humano, o social e a simetria". À proposição, em Callon-Latour, de que os estudos sociais da ciência deveriam tratar simetricamente humanos e não humanos, aqui considerada incapaz de produzir soluções efetivas aos problemas de investigação postos aos ESCT, Maia contrapõe a proposta de compreender os diversos agenciamentos entre humanos e não-humanos, a partir da ideia de pós-social, inicialmente desenvolvida por Karin Knorr-Cetina. Com isso, e sem separar as instâncias material e simbólica, ou deixar de equacionar as agências materiais (interativas com a ação de atores sociais historicamente constituídos), pretende superar o "animismo retórico" latouriano que, em seu modo de ver, mais faz confundir do que integrar natureza e sociedade.

Já na segunda parte, no quarto capítulo, "A dinâmica da expertise no 'Juicio Ciudadano' no Uruguai: Cidadania, poder e energia nuclear", Fabrício Monteiro Neves, Vinícius Teixeira Pinto e Julio Souto Salon apresentam a interessante experiência da organização da conferência de consenso sobre temas controversos em C\&T no Uruguai - nesse caso, sobre o tema da energia nuclear. Amparados na teoria das expertises de Collins e Evans, os autores investigam o papel e a importância da participação 
de cidadãos não-experts no processo de discussão, em sua interação com aqueles que possuem alguma expertise sobre o tema em questão (de modo a produzir expertise interacional e, eventualmente, contributiva). O objetivo é entender de que modo tal mecanismo de participação pública em debates sobre ciência e tecnologia pode ser considerado um alternative pathway (Hess, 2007) - um arranjo alternativo às formas clássicas/tradicionais de participação democrática em controvérsias dessa natureza.

Seguindo na apresentação de estudos de caso, Luis Reyes-Galindo investiga, no capítulo cinco, o campo da Física teórica. No texto "O papel das aproximações na Física: o caso de experimentos e teorias controversas no efeito Casimir", além de um debate a respeito das distintas formas de realizar aproximações em Física teórica - uma ação incontornável nesta especialidade, o autor procede ao estudo da controvérsia da física moderna em torno do efeito Casimir, relacionado a essa problemática. Com isso, argumenta a favor da importância do conhecimento tácito na realização das aproximações e na interpretação dos resultados dos experimentos científicos.

No sexto capítulo, intitulado "Digitalizando o câncer de próstata: pensando as interseções entre engenharia e biologia na ciência contemporânea", Marko Monteiro apresenta admirável etnografia, realizada entre 2006 e 2008, de um grupo interdisciplinar de pesquisadores na cidade de Austin, no estado americano do Texas, que se dedica a desenvolver um modelo computacional de transferência de calor em tecidos da próstata. Interpretando as práticas de pesquisa a partir da análise dos desentendimentos entre as áreas biológicas e de engenharia no projeto, e do papel que a matemática assume como língua franca na mediação dessa tensão, o autor traz notáveis contribuições para a compreensão do aspecto humano, social e cultural do desenvolvimento das tecnologias de diagnóstico e tratamento de doenças, enderençando com sofisticação uma das novas formas de representar e interferir no corpo humano que emergem das 
tentativas de obter o controle dos processos biológicos a partir de modelos computacionais.

No capítulo sete, "Risco, perigo ou oportunidade? As disputas entre política, economia e ciência acerca dos OGMS", Renata Campos da Motta apresenta discussão de fôlego sobre as disputas em torno da pesquisa e produção, comercialização e regulamentação internacional dos transgênicos. Para tanto, depois de uma discussão cuidadosa sobre o conceito de risco à luz das formulações de Niklas Luhmann e Ulrich Beck, aborda a controvérsia comercial acerca da política europeia para produtos biotecnológicos no âmbito da Organização Mundial do Comércio (OMC). Ao buscar mapear as disputas não só entre os campos científicos, político e econômico, mas também entre os distintos países em torno da existência (ou não) de riscos dos organismos geneticamente modificados, interpreta tais conflitos em termos das "relações globais de risco". Por meio de tal abordagem, voltada à complexidade, a autora contribui para abrir as fronteiras dos ESCT para um profícuo debate com a geopolítica, a economia, a ciência política, entre outras disciplinas, aqui endereçadas a partir de um olhar dirigido às dimensões sistêmicas de análise.

No oitavo capítulo, Adriano Premebida debruça-se sobre "Os interesses heterogêneos da ciência e a politização específica da vida biológica". O objetivo geral é compreender de que modo emergem novas expectativas e padrões de consumo em saúde, bem como novas formas de sociabilidade, a partir da recente expansão das biotecnologias. Mais especificamente, a questão central abordada é a tendência de as biotecnologias legitimarem-se por meio de um discurso biopolítico regido pela "codificação baseada no jogo entre verdade e opinião" (p.233). Para o autor, uma vez que a reordenação histórica das relações sociais e políticas está sujeita a modificações em função das transformações tecnológicas e da concomitante reestruturação de costumes e conhecimentos, a cir- 
culação de novos artefatos tecnológicos, "junto a uma lógica liberal de orientação pessoal quanto aos riscos na fabricação e no uso deles, estabelece reorganizações comportamentais na forma de reger uma vida segura e maneiras de experimentar a própria corporalidade em um ambiente tecnificado" (p.257). Assim, dado que a natureza passa a ser manipulada em sua própria materialidade "imanente" (o genoma) pela ciência - algo que impacta de forma inédita nos aspectos vinculados aos condicionantes biológicos da humanidade - esta se apresenta como uma zona de produtora de entrechoques políticos.

Por fim, no capítulo nono, intitulado "Nanotecnologia nos meios de comunicação: que informação chega ao público?", Noela Invernizzi e Cibele Cavichiolo debatem a cobertura da imprensa a respeito do emergente campo científico-tecnológico das nanotecnologias - que adquiriu, de acordo com dados mobilizados pelas autoras, "rápida legitimidade, caráter estratégico e significativos investimentos públicos para a pesquisa no país" (p.264). Para tanto, examinam veículos da mídia impressa brasileira, incluindo um jornal (Folha de S. Paulo), três revistas semanais (Veja, Época e IstoÉ) e duas revistas especializadas em divulgação científica (Galileu e Super Interessante), em período que vai de 2002 a 2007. A partir desta análise, as autoras concluem que, além de escassas e deficientes na abordagem de aspectos controversos e riscos potencias da nanotecnologia, as informações que chegam ao público estão, em geral, carregadas de celebracionismo e otimismo, fazendo antecipar uma série de promessas de avanços impressionantes sem, no entanto, discutir devidamente a factibilidade destes.

Feito este panorama, o leitor sentirá falta (ainda que este não esteja entre os objetivos da coletânea aqui resenhada) de um debate mais detido a respeito das inconsistências internas e demais aspectos ainda em aberto no tratamento sociológico vinculado aos distintos preceitos dos 
ESCT. Também por isso, em que pese os inúmeros méritos do livro, faz-se necessário nos dedicarmos, finalmente, a alguns questionamentos e inquietações de ordem mais geral, e talvez até externos, de modo a, quiçá, contribuir de alguma forma para o aprimoramento e alargamento das fronteiras deste profícuo campo de estudos.

Primeiro, como afastar os estudos de controvérsias em C\&T de pressupostos e teses por vezes vinculados, de saída, a um horizonte normativo liberal-deliberacionista (de fundo habermasiano), histórica e geograficamente localizado? Ainda, nesta direção, como evitar a reptícia presença de traços racionalistas no bojo dos debates sobre a necessidade de divulgação científica e educação para a ciência - como se mais e melhores informações necessariamente levassem a melhores decisões no encerramento de controvérsias científicas e tecnológicas?

Visualizados e compreendidos os interesses e mecanismos retóricos mobilizados nas disputas pelo poder no fazer científico, há algum papel para o conteúdo lógico-cognitivo na definição e encerramento das controvérsias; se sim, qual? Ademais, os rumos do desenvolvimento tecnológico-material influenciam e condicionam, de alguma forma, o desenvolvimento científico? Se sim, como? Como, e a partir de quais fatores, se estabelecem as hierarquias de poder entre os distintos atores, forças políticas e discursos que intervêm nas disputas em C\&T? Certamente, os argumentos mobilizados por Collins em defesa de sua "terceira onda", ainda que não as esgotem, talvez ensejem, como provocação e ponto de partida, promissora via de investigação para a resposta de tais perguntas.

Conforme apontado anteriormente, o livro está transversalmente ancorado na tese de que a produção do conhecimento e da ciência é histórica e socialmente contextual. Apesar disso, os autores não chegam a demostrar com clareza de que modo o contexto social das décadas de 1970 e 1980, tomado amplamente, impactou na própria constituição dessa assertiva e, 
mais amplamente, na configuração do campo de estudos a ela vinculado; ou ainda, como o contexto das décadas posteriores influenciou em sua difusão e institucionalização. É sabido que este foi um período de importantes mudanças políticas, econômicas e socioculturais, quando movimentos de contestação em distintas áreas alcançaram grande relevância e protagonismo. De que modo tal quadro pode ser mobilizado para refletirmos o surgimento dos ESCT e suas principais teses? Mais objetivamente, como se dão as homologias entre política e a teoria no que se refere ao surgimento do próprio campo dos $\mathrm{ESCT}^{3}$ ? Em vias de manter coerência com o princípio da reflexividade (um dos quatro princípios do Programa Forte), uma discussão de caráter epistemológico a este respeito contribuiria para tornar ainda mais sólido o argumento defendido pelos autores ${ }^{4}$.

Ademais, com algumas exceções, sendo a mais destacada o trabalho de Renata Motta, o contexto social que perpassa a produção de C\&T aqui abordado tende a localizar-se, em geral, em uma topologia microssociológica de análise - o laboratório, o cientista, a comunidade, o fórum deliberativo. Para além de suas indiscutíveis contribuições, tal abordagem tem passado ao largo, no entanto, do estudo de temas de suma importância, como, para citar um em especial, a economia política da produção do conhecimento científico e tecnológico - a relação dos empreendimentos científicos com as grandes transnacionais e as indústrias bélicas (integração civil-militar), o papel dos Estados, o poder do dinheiro e das altas finanças na produção da ciência, entre outros.

\footnotetext{
3 Mais especificamente, de que modo a crítica aos universalismos, o diagnóstico a respeito do fim chamadas "grandes narrativas" - e mais tarde do "fim da história" - rumo a configuração de uma "era pós-ideológica" impactam na construção de tais assertivas? Quais afinidades guardam com o aparecimento da filosofia existencialista, dos estudos sobre a linguagem, com o resgate do sujeito nos modelos explicativos, e com o giro mais acentuado à microssociologia a partir dos anos 1980? De que modo buscam apresentar uma alternativa às propostas de encontro entre agência e estrutura que passam a dominar a disciplina da sociologia a partir deste período?

4 O capítulo que chega mais perto de fazê-lo é o de autoria de Carlos Maia. Mas, dado este não ser seu objetivo, não chega a aprofundar nesta direção.
} 
Não se quer, com este apontamento, advogar pela volta da rígida separação entre contexto da descoberta e contexto da justificativa nos estudos sobre a ciência, novamente apartando o estudo das instituições científicas do conteúdo ou produto de conhecimento. Pelo contrário. Sabe-se que aspectos como os grandes interesses econômicos e geopolíticos, as desigualdades sociais, a dinâmica dos regimes produtivos e de regulação social do trabalho, os grandes movimentos de capitais, bens, serviços e pessoas, os conflitos sociais, movimentos migratórios, entre tantos outros aspectos - em um primeiro olhar considerados alheios à vida em laboratório - guardam enorme impacto na constituição das atividades cotidianas de pesquisadores e, dessa forma, em seus produtos de conhecimento. Por que não estender, então, as frutíferas metodologias dos ESCT para esforços de investigação voltados às dimensões sistêmicas e macrossociais, de modo a encontrar outras importantes determinações sociais do fazer científico, em consonância e complementação com as que têm sido buscadas atualmente? Tal esforço teria o préstimo, ademais, de ampliar o aporte e construção de conteúdos interdisciplinares no interior deste campo.

De qualquer forma, tudo somado, para além do referido mérito de sua pertinência, coerência, clareza e didatismo nas análises, a chegada desta obra ao cenário acadêmico brasileiro tem muito a contribuir não só para estes como para outros debates e reflexões, ativando e levando para mais além a compreensão sociológica a respeito do fazer científico e tecnológico no Brasil.

Edemilson Paraná é mestre e doutorando em sociologia pela Universidade de Brasília (UnB) e pesquisador-bolsista do Instituto de Pesquisa Econômica Aplicada (IPEA).>edemilsonparana@gmail.com 


\section{Referências}

1. COLLINS, H. M.; EVANS, R. The Third Wave of Science Studies: Studies of Expertise and Experience. Social Studies of Science, 32 (2), p.235-96, 2002.

2. HESS, D. Alternative Pathways in Science and Industry: Activism, Innovation and the Environment in an Era of Globalization. Cambridge, Massachusetts: The MIT Press, 2007.

3. PREMEBIDA, A.; NEVES, F.M.; DUARTE, T.R. (orgs.). Investigações contemporâneas em estudos sociais da ciência e da tecnologia. Jundiaí: Paco Editorial, 2015, v.1., 325p.

Recebido: 19.07.2016

Aceite final: 02.09.2016 